\title{
A concepção metafísica de Descartes da ciência e da representação mecanicista da natureza
}

\author{
J. R. N. Chiappin
}

Professor na FEA/USP e no Departamento de Filosofia da USP 

Neste artigo pretende-se desenvolver a concepção metafísica de Descartes da ciência e sua construção de uma nova imagem do mundo como representação mecanicista da natureza e como procedimento racional e heurístico de solução de problemas (Chiappin 1996).

O ponto de partida para a elaboração da concepção metafísica da ciência é a adoção da geometria como modelo de organização do conhecimento científico, da tese da existência de um sujeito transcendental do conhecimento com o Cogito como indivíduo racional equipado epistemologicamente para o acesso às essências, e, da tese de que o mundo é mecânico formado de extensão (massa) e movimento. Todas as explicações dos fenômenos físicos deverão ser reduzidas a explicações mecânicas, ou seja, combinações de massas e movimento. A motivação é a aplicação do princípio da autonomia da ciência no mesmo estilo que a geometria. A ciência deveria sustentar sobre seus próprios fundamentos que, seguindo o modelo geométrico, consistiriam de conceitos primitivos, massas e movimentos, e, portanto, simples conceitos derivados estabelecidos por definições precisas, assim como de proposições formadas desses conceitos e conhecidas como autoevidentes, como por exemplo, em Descartes, com os princípios da inércia, da quantidade de movimento e dos choques (Descartes 1963a, 1985c). A partir de uma base semelhante ou igual a essa deveriam ser derivadas rigorosamente todas as demais proposições do conhecimento científico. A física de Galileu (1954) representada e desenvolvida na linguagem geométrica forneceu o exemplo concreto e bem sucedido de como construir uma ciência, no caso do movimento, no estilo geométrico dependente apenas de seus próprios fundamentos. Assim, a natureza da ciência é dada por seu método e não por seu objeto e seu modelo é a geometria.

Descartes desempenha um papel, relativamente a Galileu, de um filósofo engenheiro que desenvolve, no seu Discurso do método (Descartes 1985a), um sistema especialista a partir dos trabalhos de Galileu (1954) se propondo a universalizar o método 
desenvolvido por Galileu de construir uma ciência como autônoma (Galileu 1954, 1991) e que consistia em adotar a geometria como forma de organizar o conhecimento científico, e, do mesmo modo, os experimentos mentais como método para encontrar as proposições universais e necessárias que deveriam ser colocadas na base deste conhecimento. A natureza do conhecimento é conhecimento certo devendo ser organizado pela ordem e pela medida (Descartes 1971, 1985a), como os elementos mais básicos e universais da geometria, que deveriam ser encontrados em todos os assuntos para fazerem deles ciências.

A exigência de uma abordagem geométrica do estudo dos fenômenos naturais, particularmente, da teoria do movimento dos corpos, dissolveu a natureza física em pura quantidade, especificamente em extensão e movimento. Assim como na geometria, a abordagem de solução dos problemas da física deve sempre se reduzir a uns poucos conceitos e proposições básicas, neste caso, todos os fenômenos devem ser reduzidos, a espaço, a um tempo geometrizado ou espacializado, portanto, mensurável pelo mesmo padrão ou escala, e, também, a massa, que é o mesmo que o volume e densidade que pode estar contido em um ponto sem dimensão.

O objetivo de Descartes (1963a, 1963b, 1985a, 1985b) era o de dar legitimidade ao modelo de Galileu de ciência e da imagem do mundo a ele associado que é o mundo mecânico, mundo de quantidades, de massas e movimento. O instrumento dessa legitimidade foi a construção de um fundamento metafísico para a natureza mecânica do mundo, para o indivíduo como sujeito transcendental capaz, por seu aparato epistemológico, de acesso direto às essências e, portanto, de conhecimento dos fenômenos da natureza, e, para o método de transformar o conhecimento em conhecimento certo, portanto, conhecimento demonstrado com modelo na geometria. O processo de conhecimento da natureza pelo indivíduo se dá por meio de um procedimento racional operacionalizado por um método, no caso, o método sintético (organização e exposição geométrica) e o analítico (procedimento de 
descoberta) ambos formados de um conjunto de regras voltadas para a realização de uma tarefa que é aquela, de modo geral, de resolver problemas. A geometria é a forma mais bem acabada e bem sucedida de como exercer a atividade de resolver problemas em quaisquer áreas passíveis de ordem e medida, e, isso, para alguns, por exemplo, Locke, em áreas onde mesmo não há quantidades, como a moral (Locke 1974).

Com esses componentes metafísicos, Descartes (1985a, 1985b) se propõe a construir a ciência como um domínio autônomo, um meio termo entre a religião e o ceticismo. Nos pilares destas duas substâncias finitivas, que tornaria o homem fim e não meio na natureza, uma ciência mecânica (natureza física) matemática (organizada e representada pela linguagem matemática) para dar conta, seguindo o modelo de Arquimedes, dos fenômenos naturais que de modo concreto estava em andamento com Galileu (Koyré 1966, 1979) e que deu origem ao programa mecanicista, com a construção de modelos de massas e movimento como o meio legitimo de proporcionar explicações dos fenômenos da natureza.

A organização geométrica da física está relacionada com a ideia de um conhecimento racional da natureza. Esse conhecimento racional da natureza relaciona-se com a ideia da construção de um sistema axiomático que funciona como uma base estabelecida como verdadeira e conhecida como certa, com a qual se pretende proporcionar decisões conclusivas quanto ao valor de verdade das proposições descrevendo os fenômenos naturais. Essa aplicação é similar ao uso que Descartes faz, como parte também do programa do racionalismo clássico, do método racional para construir a metafísica como ciência. Essa construção, que se dá de maneira analítica, portanto, como um meio de mostrar como encontrar as proposições verdadeiras, que compõem a base do conhecimento, e, ao mesmo tempo, mostrando que elas são conhecidas como certas.

A proposta de fundamentação científica da metafísica ocorre em sua obra Meditações Metafísicas (Descartes 1984a, 1967) que 
é, ao mesmo tempo, a fundamentação metafísica do mundo mecânico, enquanto extensão e movimento, dando origem a uma nova imagem do mundo e de que o indivíduo racional, o Cogito (Id., Ibid. 1984a, 1967) estabelecido como sujeito transcendental, pode conhecer com conhecimento certo. Meditações Metafísicas é uma obra de Descartes em que aparecem todos os elementos relevantes para a construção de uma nova imagem do mundo centrado nas substâncias do Cogito, o indivíduo racional, e do mundo como extensão e movimento, os elementos para desenvolver o conhecimento como conhecimento certo segundo a ordem das razões. Assim, o método, nessa obra, funciona como um método de descoberta ensinando como construir uma base para o conhecimento.

A metafísica, como ciência, construída como a base mais fundamental para todo o conhecimento é, ela mesma, um sistema de conhecimento, e capaz de proporcionar os meios para garantir como as proposições que formam essa base são verdadeiras e conhecidas como certas. O método da dúvida é um método auxiliar que tem um papel importante em fazer com que as proposições básicas da metafísica tenham essas qualificações de serem verdadeiras, como as proposições "Eu sou, Eu existo", "Eu sou uma coisa pensante", "O espírito é mais fácil de conhecer que o corpo" etc., e sejam conhecidas como certas.

Do ponto de vista do conteúdo, encontram-se expressas, na metafísica, tanto as condições para a possibilidade do conhecimento certo da natureza física quanto aquelas sobre o conhecimento do próprio indivíduo e de seu comportamento. Algumas dessas condições são, por exemplo, a construção do modelo do indivíduo como racional, a construção de um modelo do mundo cuja essência é a extensão e movimento caracterizando-o como mecânico, o modelo de Deus como substância infinita, o experimento mental do método da dúvida, o método analítico utilizado pelo método da dúvida e o experimento mental do gênio maligno (o futuro demônio de Maxwell), o método geométrico de resolver 
problemas ou seja de construir o problema para o qual já se sabe a resposta e, neste caso, um método de legitimação.

O modelo do indivíduo como racional contemplado por Descartes é aquele descrito em uma passagem da Regra 1 na qual se afirma:

Que pense exclusivamente em aumentar a luz natural de sua razão não para resolver esta ou aquela dificuldade escolar, mas, para que, em cada circunstância da sua vida, a sua inteligência mostre à sua vontade o que deve escolher (Descartes 1971, p.13) .

O modelo de escolha racional de Descartes reduz-se, portanto, à atividade de duas faculdades, o entendimento e a vontade. As faculdades do entendimento e da vontade interagem, cada uma em suas funções, para produzir uma decisão, com certeza, sobre o problema em questão. O método é um instrumento que, ao mesmo tempo dependente da vontade, serve para trazer a vontade a operar junto ao entendimento e sob seu controle. A vontade trata das preferências e dos fins que são especificamente características individuais, portanto, subjetivas. A função do entendimento, por sua vez, refere-se à seleção dos meios para a realização dessas preferências e fins e, por aqui, deve fazer o ajuste dessas preferências e fins às restrições internas e externas que aparecem frente ao indivíduo como objetivas e fora de seu controle. A aplicação do método da dúvida na busca das primeiras certezas, como conduzida nas Meditações Metafísicas, é um modelo da operação deste modelo de escolha racional de Descartes $(1967,1985$ a).

Com esses recursos epistemológicos, o indivíduo é capaz, pelo uso do método racional, como um conjunto de regras, de produzir, no processo de decisão acerca das proposições que descrevem o mundo, conhecimento certo acerca da natureza física, e também acerca de sua própria natureza.

Em relação ao conhecimento do indivíduo quanto à sua própria natureza, Descartes está preconizando uma teoria da ação 
humana, como teoria da escolha racional das ações, que seria o fundamento de seu projeto de uma moral como ciência e que será utilizada pelos contratualistas começando com Hobbes.

Seus elementos são a forma geométrica de organização do conhecimento, o atomismo mecânico formado de massas invisíveis em movimento, os princípios da quantidade de movimento, o princípio da inércia, as leis dos choques, e a forma geométrica de resolver problemas entendida como método analítico e o método sintético de construir provas.

A teoria física com esses recursos funciona para o cientista como um instrumento para tomar decisões quanto ao valor de verdade das proposições que descrevem os fenômenos da natureza física obtidas por generalizações da experiência. Essas proposições como generalizações empíricas a partir da experiência podem ser intuídas como verdadeiras, mas não são conhecidas como certas. Elas apenas adquirem essa condição quando forem integradas a um sistema axiomático assentado em uma base do conhecimento conhecida como certa.

Desta forma, à medida que decisões sobre a verdade dessas proposições são tomadas, pela construção de uma prova a partir da base do conhecimento que no caso é a base formada dos princípios de mecânica, elas, no caso de serem verdadeiras por possuírem uma prova, são agregadas à teoria física fazendo expandir o conhecimento sobre a natureza. No entender de Duhem, a física mecanicista nasceu no século dezessete com Galileu, Huygens, Mersenne e Pascal, todos contribuindo para seu estabelecimento e seu progresso, juntamente com o desenvolvimento de uma metodologia e de uma filosofia associadas.

Para Duhem, entretanto, Descartes é quem primeiro desenvolveu esta nova concepção de conhecimento e da ciência, pela construção de um novo quadro do mundo, segundo o modelo geométrico, que justifica metafisicamente a teoria mecânica como a estrutura unificadora de toda a ciência. Descartes constrói assim uma concepção metafísica da física como um programa de pes- 
quisa que será demolido tanto pelo desenvolvimento científico quanto epistemológica e metodologicamente pela construção do programa do racionalismo neoclássico com Duhem, Poincaré e os positivistas lógicos.

A teoria da ciência com a qual Descartes pretende justificar metafisicamente a física mecanicista como física teórica compreende uma metafísica, uma lógica da ciência (metodologia) e uma teoria física propriamente dita. Além dos elementos acima, a justificação metafísica da teoria mecanicista como teoria física é articulada, por Descartes, através de um sistema que torna a metafísica não apenas uma ciência, como também uma base para deduzir, e consequentemente legitimar, os princípios da física mecanicista como princípios causais de fenômenos naturais.

Tanto a física como a metafísica, segundo esta concepção, têm por objetivo oferecer explicações causais e são construídas através do mesmo método. A ontologia cria um mundo de causas mecânicas, entidades com extensão (massa), forma geométrica e movimento, e um sujeito que pode conhecer com certeza esse mundo. A epistemologia garante as condições do sujeito para a apreensão das essências e das causas eficientes no mundo, e, por aqui, para um conhecimento certo desse mundo mecânico. A metodologia, por seu turno, define a natureza e os meios para construir a teoria física e para resolver problemas (Descartes 1985 b , p. 7-78).

A axiologia da teoria da ciência de Descartes tem como fim primordial a elaboração de uma concepção de ciência para demarcar, por um lado, a ciência (ou a física e a metafísica) da fé (ou da religião), de tal modo que a primeira se torne autônoma relativamente à segunda e, por outro lado, a demarcação da ciência ocorra relativamente ao ceticismo.

De um ponto de vista metodológico, a primeira demarcação ocorre entre uma abordagem racional e uma abordagem via revelação, entre um modo sistemático e ordenado de buscar o conhecimento e aquele baseado em uma via de inspiração. Essa 
demarcação é feita em cima da pressuposição da existência de uma base do conhecimento formada de proposições verdadeiras que são conhecidas com certeza e da existência de um método para proporcionar decisões conclusivas sobre o valor de verdade das proposições. Essa é propriamente a demarcação entre ciência e religião.

A segunda é estabelecida tanto pela apresentação do sucesso do método em produzir conhecimento certo da natureza física quanto por meio de uma abordagem reflexiva sobre os fundamentos do método racional que se assenta sobre uma análise das faculdades do conhecimento. Por esse motivo, a concepção cartesiana do conhecimento e, por extensão, toda a concepção clássica de Descartes a Kant, é denominada de epistemologia com sujeito.

O conhecimento com certeza demandado por Descartes, e pelos demais pensadores clássicos, com o objetivo de definir a ciência como conhecimento certo, só é possível pela elaboração das condições epistemológicas do sujeito, ou seja, pela construção de um sujeito transcendental. O estudo das faculdades do conhecimento é central em definir a natureza e as características do método do conhecimento que é o método racional. A atividade científica é definida como uma busca metodológica de explicação dos fenômenos físicos. Descartes desenvolve uma estrutura metafísica para estabelecer as condições ontológicas e epistemológicas pelas quais o conhecimento mostra-se autônomo e unificado; uma visão metafísica do conhecimento que o separa radicalmente de uma concepção aristotélica.

A teoria cartesiana da ciência, para alguns autores como Duhem, representa a contribuição mais importante para o rompimento radical e profundo com essa concepção tradicional. Trata-se de uma revolução no modo como concebemos e interpretamos a natureza do mundo e do conhecimento, embora não se situe no nível da ciência propriamente dita. A concepção aristotélica de ciência estabelece a existência de diferentes ordens do conhecimento, cada uma com seus objetos específicos e com seus méto- 
dos apropriados. O programa de Descartes requer a abolição da demarcação aristotélica entre física e metafísica; a única que ele preserva é entre física e religião. O pluralismo e a independência de objetos e métodos do sistema aristotélico são substituídos pela unidade de objeto e de método; tal unidade consiste na própria unidade de um conjunto de ideias simples e na unidade mesma da razão.

Descartes constrói a razão como a faculdade do conhecimento. A epistemologia, e não a ontologia, adquire precedência no processo de conhecer. Sua epistemologia constrói um sujeito transcendental (o Cogito) que representa o conjunto de todas as condições para tornar o conhecimento possível e autônomo. O Cogito resume as condições ideais dos meios de conhecer, correspondendo às faculdades, objetos e ao método. A razão é a faculdade do conhecimento, as ideias inatas constituem tanto seu objeto como o conjunto de regras que tornam operacional a concepção metafísica da natureza do mundo e do conhecimento, e o método proporciona o meio de resolver problemas. Todos estes elementos são articulados de modo a desenvolver a autonomia da ciência. Duhem, por exemplo, caracteriza esta revolução, no pensamento, como centrada ao redor da unificação da metafísica e da física, bem como da formulação de uma nova lógica (metodologia) para definir o conhecimento. Ele afirma:

Ao final do século XVI e no início do XVII, o espírito humano sofreu uma das maiores revoluções que teriam abalado o mundo do pensamento. As regras lógicas, traçadas pelo gênio grego, haviam sido aceitas até aquele momento com inteligente docilidade pelos mestres da escola, e, em seguida, com estreita servidão pela escolástica em decadência. Neste momento, os pensadores as rejeitam; pretendem reformar a lógica, forjar novamente os instrumentos de que se serve a razão humana, e, com Bacon, criar um novum organum; eles rompem as linhas de demarcação estabelecidas pelos peripatéticos entre os diversos ramos do saber humano; a distinção, que servia para delimitar exatamente as questões e para 
delimitar cada método com o campo que lhe é próprio, torna-se um termo ridículo, do qual se apoderou a comédia; então, vê-se desaparecer a antiga barreira que separava o estudo dos fenômenos físicos e de suas leis da busca das causas (Duhem 1893).

Segundo Duhem é Descartes quem faz a fusão da metafísica com a física. Como ele mesmo diz:

veem-se as teorias físicas tomadas por explicações metafísicas, os sistemas metafísicos buscando estabelecer, por via dedutiva, as teorias físicas. [...] Mas aquele que mais contribuiu para romper a barreira entre a física e a metafísica foi Descartes (Id., 1893b, p. 75; os itálicos são nossos.)

A percepção dos filósofos e cientistas do século XIX é que Descartes contribuiu, sobretudo, para definir a teoria física como buscando explicações causais dos fenômenos físicos e para conceber a própria física como um sistema racional. Além disto, Descartes e Bacon desenvolveram a nova lógica da ciência que substitui o organum aristotélico. Esta lógica busca operacionalizar a concepção cartesiana do conhecimento e do mundo com uma metodologia do raciocínio científico (ordem e medida) e com um método para construir a teoria física (Descartes 1985a, p.116). Para alguns filósofos, principalmente aqueles que flertam como uma concepção intelectualista do racionalismo, o Novum Organum de Bacon não é representativo de uma física clássica ou influente em seu desenvolvimento. Este é o caso de Duhem (1896a, p. 470).

As teses ontológicas de Descartes, acerca da separação entre mente e corpo e dos atributos quantitativos como propriedades essenciais dos corpos, são apresentadas de modo a tornar o mundo corpóreo tanto matemático quanto efeito puro de causas mecânicas. Com essas teses, ele busca institucionalizar, sob uma perspectiva ontológica, a dicotomia galileana entre qualidades primárias e secundárias. Essa dicotomia ontológica é que garante as condições para a física matemática, pois, as coisas no mundo 
são quantidades. A categoria aristotélica da qualidade é tornada um elemento derivado no sistema cartesiano. Do ponto de vista ontológico, a metafísica cartesiana estabelece, em primeiro lugar, a tese da separação entre corpo e mente e, em segundo, que o atributo essencial da mente é o entendimento. Ela estabelece ainda que os atributos reais do corpo são propriedades matemáticas, a saber: extensão, figura e movimento. Os compromissos ontológicos de Descartes eliminam formas substanciais (qualidades) como atributos essenciais do corpo, retendo apenas os elementos quantitativos. Novamente é Duhem quem entende claramente que o sucesso do objetivo da fundamentação metafísica da nova imagem do mundo com Galileu exige de Descartes que ele elimine as qualidades do estudo das coisas materiais. Ele tece a seguinte observação: "Eliminar inteiramente as qualidades do estudo das coisas materiais, este é o objetivo e como que a característica da física cartesiana (Duhem 1896a, p. 471).

Subjacente a essa ontologia, encontra-se um compromisso com a ideia de que a epistemologia precede a ontologia, decorrente da admissão cartesiana da matemática como o meio para representar o conhecimento, e do método dedutivo-geométrico como o recurso formal para organizá-lo. Sobre estes dois pressupostos epistemológicos, acerca da representação (símbolos algébricos) e da organização da mesma (sistemas matemáticos e geométricos), repousa o critério cartesiano de racionalidade: a ordem das razões. A característica mais abstrata e essencial do que é a ciência, ou o novo critério de racionalidade, encontra-se baseada em uma idealização/abstração do método dedutivo-geométrico.

Essa abstração tem por objetivo aplicar o critério da ordem das razões (como um critério de racionalidade) a domínios que transcendem a matemática e a geometria. No entender de Descartes, a ordem segundo a qual uma disciplina se encontra organizada a caracteriza como conhecimento. Desse modo, demarca-se o conhecimento científico da revelação e da opinião. Descartes, com efeito, nos menciona: 
Aquelas longas cadeias, compostas de raciocínios muito simples e fáceis, que os geômetras costumam empregar para obter suas mais difíceis demonstrações, proporcionaram-me ocasião de supor que todas as coisas que podem se colocar sob o conhecimento humano são interconexas do mesmo modo. E penso que, contanto que nos abstenhamos de aceitar qualquer coisa como verdadeira quando esta não o é, e que sempre mantenhamos a ordem requerida para deduzir uma coisa de outra, nada pode haver remoto demais para ser afinal atingido ou muito bem ocultado para ser descoberto (Descartes 1985a, p. 120; os itálicos são nossos).

Em sua forma mais abstrata e ideal, a ciência constitui-se em um sistema racional perfeito, sendo definida por meio de um sistema axiomático ideal de razões, composta de princípios e conceitos mecânicos como extensão (massas) e movimento bem estabelecidos dos quais se derivam, através de princípios lógicos e princípios mecânicos, as demais proposições explanatórias dos fenômenos da natureza. Esse sistema axiomático, contendo todo o conhecimento, possui por objetivo atingir o princípio epistemológico fundamental da filosofia cartesiana: a unidade de toda a ciência. O princípio da unidade lógica constitui-se na condição ideal para a perfeição da ciência, e ele é realizado efetivamente pela eleição da mecânica como a estrutura física do mundo.

A árvore do conhecimento, descrita nos Princípios da Filosofia (Descartes 1985c, p. 186), expressa a ideia da unidade do conhecimento científico de acordo com a noção de uma ordem das razões articulando todas as ciências (Id., 1985a, p. 120). Estas últimas pertencem ao mesmo sistema axiomático, à mesma ordem das razões. Rigorosamente, contudo, trata-se de um sistema monista: há apenas uma única ciência, a ciência unificada pela mecânica. Todas as demais ciências (seus conceitos e leis) são a ela redutíveis. Se, sob a perspectiva formal, a unificação é compreendida em termos estritamente dedutivos (a partir de um 
sistema racional), do ponto de vista do conteúdo, o princípio da unidade lógica é representado pela teoria mecânica. Com efeito, essa teoria constitui-se na estrutura de unificação de toda a ciência, aparecendo como uma teoria da matéria. O princípio de unidade lógica requer que todas as ciências, a moral e a medicina, sejam dela deduzidas. Contudo, a própria teoria mecânica, por seu turno, é deduzida da metafísica. Semelhante concepção da metafísica, como implicando lógica ou dedutivamente a física, constitui-se em uma visão fundacionalista da mesma.

A metafísica estabelece condições gerais, abstratas e ideais para quaisquer teorias mecanicistas e da matéria. Pretende-se que a teoria mecânica proporcione explicações (mecânicas e causais) de todos os fenômenos físicos. A garantia, para tanto, depende da ideia de que possuímos o poder de conhecer, com certeza, os princípios causais dos objetos.

A epistemologia de Descartes define o sujeito que conhece como contendo as condições de semelhante conhecimento estabelecendo o objeto e os meios de conhecer. A primeira tese epistemológica estabelece que o entendimento é a faculdade do conhecimento (Descartes 1984a); a segunda tese, por sua vez, formula os meios disponíveis à nossa razão para implementar a aplicação do método axiomático ideal: a intuição e a dedução (Id., 1985b, p. 14). Através da intuição, possui-se acesso direto à essência das coisas e, assim, às verdades (ideias inatas); pela dedução (ou coleção de intuições), derivam-se outras verdades a partir das primeiras intuições. A terceira tese epistemológica estabelece que os critérios de verdade são a clareza e a distinção através dos quais os princípios básicos da ciência podem ser reconhecidos: os princípios autoevidentes e as verdades (os conceitos básicos ou naturezas simples). A epistemologia cartesiana contém ainda a ideia de que todas as proposições científicas são verdadeiras ou falsas e de que a ciência é caracterizada metodologicamente por proporcionar meios sistemáticos e organizados para proporcionar decisões conclusivas acerca de suas proposições. 
O modelo de escolha racional na ciência é operacionalizado, no entender de Descartes, definindo-se: (1) os objetos básicos do conhecimento, a saber, (a) as ideias inatas ou as naturezas simples (extensão, figura e movimento), (b) os princípios autoevidentes (os princípios da quantidade de movimento, da inércia e das colisões), (c) as leis da razão, isto é, as noções comuns (por exemplo, se $A=B$ e $C=B$, então $A=C$, os princípios da identidade e de contradição e todas as regras matemáticas). São com esses elementos que se constrói uma base última, mecânica, do conhecimento. Ela é formada de proposições verdadeiras e que são conhecidas com certeza; (2) o método experimental representa um meio para descobrir novas proposições (leis) empíricas, seu valor de verdade (tais como, as leis de reflexão e de refração da ótica). A análise das experiências, tanto mentais quanto factuais, elaboradas por Descartes do fenômeno do arco-íris (Descartes 1963, p. 749-761) e a elaboração da lei de refração (Id., Ibid. 1963, p. 664-678), podem ser tomadas como exemplos; e (3) o método matemático-mecânico (álgebra) que estabelece o vínculo entre as leis empíricas e a base conceitual mecânica (Id., 1967, p. 581-585).

O método, particularmente o analítico, é o instrumento pelo qual se faz a conexão entre a base última do conhecimento e aquela constituída pelas leis empíricas. O método analítico é o procedimento para descobrir as ideias intermediárias que farão a conexão. Essa conexão permite, por assim dizer, construir um conhecimento com certeza da lei empírica que o método empírico por si só não poderia proporcionar, exceto pelo valor de verdade. Dessarte, o problema cartesiano consiste em explicar mecanicamente as leis empíricas e os fenômenos físicos, ou, em outras palavras, conectar tais leis empíricas ao sistema mecânico expresso por meio de sua base, a base mecânica. Neste ponto aparece o papel metodológico de um dos componentes mais importantes da abordagem de solução de problemas de Descartes que é aquele da ideia intermediária. A expressão metodológica que define o método de abordagem de soluções de problemas é o método analítico 
(Descartes 1967 p. 581-585), que é o instrumento para descobrir tanto os componentes da base quanto as ideias intermediárias que fazem a conexão entre a base e as leis empíricas relativamente às quais pretendemos obter um conhecimento demonstrado.

Segundo o método analítico, precisa-se sempre assumir o problema como resolvido, portanto, pressupor a solução do problema, e tê-la como um novo dado do problema, e, então, a partir dos outros dados, considerados como pressupostos, e, ainda outros assumidos como auxiliares, demonstrar que essa é a solução. O importante nesta demonstração é encontrar a ideia intermediária, ou ideias intermediárias, que liga esses dois componentes, os dados do problema e o dado representando a solução do problema que foi assumido como resolvido. Desta forma, tanto os dados do problema como a assumida solução do problema são guias para a solução do problema que é encontrar as ideias intermediárias.

A concepção metafísica da ciência de Descartes como um sistema axiomático ideal, o princípio da unidade lógica e a doutrina epistemológica do acesso direto, pelo sujeito, à verdade constituem os elementos básicos de sua teoria do progresso, descrita através de uma proposta que denomino uma "teoria da cascata da verdade" (Chiappin 1996).

O princípio que caracteriza a teoria da cascata da verdade afirma que certas verdades e o conhecimento teórico são dados no início do sistema científico, e que, através do método dedutivo como uma coleção de intuições - pode-se distribuir a verdade, do topo até a base, por todos os componentes derivados do sistema. Essa teoria envolve ainda duas concepções de verdade: a teoria da correspondência (adequação da ideia ao objeto) e da coerência (consistência interna entre as ideias). Por um lado, os pressupostos básicos do método axiomático supostamente representam coisas reais no mundo, e isto é garantido por sua doutrina epistemológica do acesso à verdade. Por outro, a visão da teoria física como um sistema axiomático ideal encontra-se baseada na ideia de que 
noções comuns (leis matemáticas) levam de verdades a verdades, em conformidade com a doutrina da coerência.

Descartes supõe que a verdade dos pressupostos básicos confere objetividade e realidade a todo o sistema, bem como para suas consequências mais particulares, através da estrutura dedutiva. Portanto, o estatuto realista da ciência cartesiana encontra sua legitimidade no conteúdo da base conceitual mecânica, não em suas consequências observacionais.

A lógica da ciência de Descartes (metodologia) tem por papel definir as regras e o método para operacionalizar sua concepção do que é a ciência, descrito acima. Nesse nível, trata-se de implementar o método abstrato e universal da ordem e da medida, bem como a própria teoria da cascata da verdade. Essa metodologia envolve os seguintes procedimentos: o analítico, o enumerativo, aquele com respeito à ordem, e o sintético (Descartes 1985a, p. 120). Ela funciona para resolver problemas, para auxiliar a encontrar, através da cadeia das razões, a conexão entre leis empíricas e a base conceitual do sistema axiomático ideal. Uma vez obtido esse vínculo, pode-se pretender que uma explicação mecânica dessas leis tenha sido proporcionada. Portanto, trata-se de um método para construir explicações mecânicas dos fenômenos físicos.

Esse método, por sua vez, foi motivado pelo próprio método cartesiano de resolução de problemas geométricos, transformando-os em problemas algébricos. Consequentemente, Descartes não apenas busca uma física construída de acordo com uma ordem dedutiva de razões (modelada a partir da imagem proporcionada pela própria geometria), mas uma que também se constitua em uma característica universal, uma cadeia de razões expressa através de símbolos matemáticos, em conformidade à imagem da álgebra, além daquela característica do raciocínio geométrico. O emprego da álgebra levou Descartes a discutir o problema da representação do conhecimento. No seu entender, o conhecimento é representacional, e sua linguagem, matemática.

Depois da noção de ordem, o conceito mais importante de 
sua concepção de ciência é aquele de medida, que permite a algebrização da física estabelecida como quantidade através da afirmação que a substância do mundo é a extensão. Medida é aquilo que há de comum entre duas coisas, e, que, portanto permite estabelecer uma relação entre elas. Com esse conceito, Descartes estabelece as duas condições formais para a matematização/ geometrização da física: ordem e medida (Descartes 1985b, p. 19). Assim, a relação entre os princípios verdadeiros e autoevidentes da teoria física e sua base empírica, constituída de leis empíricas, é efetuada não apenas através de uma cadeia de razões, mas também por meio de uma ordem de razões que deve ser representada na linguagem algébrica.

A imputação da linguagem algébrica à física como sua representação consiste em trazer toda uma série de recursos heurísticos do cálculo algébrico para operacionalizar a arte de resolver problemas físicos. Esse é o caso dos benefícios dos recursos heurísticos do cálculo algébrico que Descartes já tivera oportunidade de apreciar ao representar a geometria e seus problemas na linguagem da álgebra. Com efeito, a algebrização da geometria possibilita a passagem de uma geometria figurativa ou qualitativa a uma quantitativa ou analítica, almejada por Descartes na física. Ele observa que a física, para ser abordada através de recursos quantitativos, deve ser constituída por elementos dessa ordem, por elementos mensuráveis, isto é, por elementos mecânicos. Descartes afirma que a física não pode ser matemática a menos que seja mecânica. Ele busca uma física que apresente a eficiência e a certeza oferecidas à geometria pela álgebra.

A epistemologia e a metodologia cartesianas encontram-se intimamente vinculadas. Por um lado, sua epistemologia postula que os verdadeiros objetos de nosso conhecimento são ideias em nossas mentes, cuja natureza mais íntima consiste na representação de algo. Tais ideias são, desse modo, o que ele considera como representações interpretadas como estados ou objetos mentais. Trata-se, com efeito, de um conceito de representação 
não apenas novo, mas amplo e radical, que determina a natureza mesma da reflexão clássica sobre a ciência, a saber, que a análise do método científico deve envolver um exame das faculdades cognitivas do conhecimento. Esta análise se inicia, assim, por uma teoria do conhecimento.

No interior do pensamento clássico, reside uma identidade indissolúvel entre razão (epistemologia) e método (metodologia). A verdade é definida pelo princípio da identidade entre ideia e objeto. Contudo, como ter certeza acerca dessa identificação se se possui acesso apenas às ideias (ideias inatas, que são essências)? Essa concepção de representação, por interpretála como um objeto mental, vinculando o estudo do método ao exame de nossas faculdades do conhecimento, acaba por levar a uma relação biunívoca entre tais faculdades (epistemologia) e o próprio método científico (metodologia), a saber: entre o entendimento e o método axiomático ideal, a imaginação e o método hipotético-dedutivo, e os sentidos e o método experimental. Essa análise das faculdades do conhecimento, com a ajuda da qual ele determina a sua função, objeto e limite, é o meio para demarcar a ciência do ceticismo (Descartes 1984a )

As duas primeiras meditações (Id.,, Tome II, 1967) fazem parte da estratégia de Descartes para demarcar sua concepção do conhecimento do ceticismo assim como da religião. A compreensão da função do conhecimento, de seu objeto e de seus limites, permite que nos restrinjamos ao estudo apenas dos assuntos em que o método racional possa ser aplicado, deixando-se, por exemplo, de aplicá-lo à religião. Evita-se, por esse meio, gerar inconsistências e paradoxos que dão origem ao ceticismo.

Quando a intuição, por exemplo, não pode apreender a essência dos vínculos entre os fenômenos físicos e o sistema mecânico de princípios e conceitos, a razão, então, é substituída pela faculdade da imaginação. Essa faculdade, por seu turno, trabalha com hipóteses e conjecturas (Id., 1963 Régle VIII, Tome I). Nesse caso, o método axiomático ideal é substituído pelo método 
hipotético-dedutivo. As hipóteses são consideradas satisfazer a exigência racionalista da construção de uma cadeia de razões entre os princípios e as leis empíricas. Do ponto de vista desse método (hipotético-dedutivo), como tais hipóteses são apenas prováveis, e não absolutamente verdadeiras, podem-se apresentar hipóteses diferentes para o mesmo conjunto de fenômenos.

Nesse nível, faz-se recurso à terceira faculdade do conhecimento, os sentidos, e ao método a ela associado em concomitância com a razão, o método experimental. Esse método possibilita a obtenção das leis empíricas e de relações específicas entre os elementos quantitativos básicos, tais como ângulos, comprimento, movimento etc. (As leis de reflexão e de refração da luz e as relações quantitativas envolvidas na explicação do arco-íris - o ângulo do mesmo - constituem exemplos do emprego desse tipo de método). Com base nessas leis e nas relações quantitativas, é possível escolher entre hipóteses rivais para explicar os fenômenos físicos. A não apreensão das essências não é razão para ceder ao ceticismo quanto às possibilidades do conhecimento. As faculdades podem fazer uso do método racional que se ajusta à ideia de fazer suposição ou hipótese sobre a natureza das coisas, e, então, extrair consequências dessas suposições, e, posteriormente, pela análise destas últimas, e, por fim, buscar evidências de sua certeza moral. Um conhecimento crescente das hipóteses pode conduzir à apreensão de uma intuição do vínculo essencial na ordem das razões do qual só se tinha apenas uma hipótese anteriormente.

Contudo, qual é a interpretação cartesiana do método experimental? É o método para escolher entre hipóteses ou teorias alternativas. Elas podem ser selecionadas na medida em que, para a interpretação clássica, a refutação de uma constitui-se em uma confirmação da outra. Com efeito, como Duhem nota, no interior da interpretação clássica desse método, "a destruição de um dos dois sistemas em oposição garante a certeza do outro, da mesma forma que, em geometria, o absurdo de uma proposição acarreta a verdade de sua contraditória” (Duhem 1985, p. 109). 
A aplicação desse método em física se expressou na ideia de que se estava diante de um Experimentum Crucis como utilizado por Newton (Newton 1672; Silva e Martins 1996, p. 313-217) em sua teoria das cores. Newton tinha a intenção de usar a experiência dos prismas para mostrar que as cores não eram criadas, mas separadas da cor branca pelos diferentes graus de refrangibilidade (Silva 2003, p. 53-65). A origem dessa concepção de experimento, como uma decisão conclusiva, para decidir entre a verdade ou falsidade de uma proposição aparece pela primeira vez em Bacon com o nome de "instâncias cruciais" (Bacon, seção XXXVI, 1984).

Desse modo, segundo Duhem, os pensadores clássicos, tais como Galileu, Descartes, Bacon e Newton, interpretam o papel do método experimental como similar àquele do método geométrico, isto é, como um método de prova, um procedimento tanto de refutação como de validação (Duhem 1985, p. 109). Assim, o método experimental, com a construção de experimentos cruciais, é interpretado como uma versão do método de redução ao absurdo para demonstrações geométricas (Descartes, 1985a).

Como observado, a concepção clássica desse método consiste em tomá-lo como um procedimento de decisão acerca do valor de verdade das proposições científicas, isto é, dada qualquer proposição desse tipo, pode-se, através do método, provar da verdade ou falsidade de qualquer proposição. No entanto, o estabelecimento desse item, para um racionalista, não se revela suficiente para a constituição do conhecimento. No entender de um racionalista, como Descartes, exige-se ainda que semelhante verdade, para ser categorizada como conhecimento, se enquadre no interior de um sistema racional. O método experimental apenas seleciona as verdades a serem organizadas em um sistema; uma prova completa é obtida ao se apresentar uma cadeia de razões ligando o sistema mecânico de princípios e conceitos às leis ou fatos empíricos a serem explicados.

Fica claro, portanto, que o cientista que toma essas decisões é um ente racional no sentido de que as teorias físicas são suas 
opções de descrições da natureza, que podem ser suas criações, enquanto as leis empíricas são as restrições objetivas que a natureza impõe às suas opões de descrições. A racionalidade do cientista o conduz a escolher o melhor ajuste entre as teorias físicas e as proposições, e com isso estabelece-se o valor de verdade das proposições e seu conhecimento como certo. Descartes parece assim buscar, com seu modelo de escolha racional, uma síntese entre ambas as abordagens teórica e experimental. Em termos de uma concepção moderna de escolha racional, as teorias físicas são as preferências dos cientistas quanto à descrição da natureza, enquanto as proposições empíricas são as restrições que a natureza física impõe à livre construção das teorias físicas.

Uma classe especial de representações, selecionada através da aplicação da álgebra à teoria física, preencherá a estrutura axiomática com conteúdo cognitivo. A ideia de modelar a teoria física a partir da álgebra leva Descartes a considerar as quantidades como os únicos conceitos primitivos legítimos de nossa ciência. A exigência (implícita) de um isomorfismo entre um sistema relacional numérico, com a propriedade de aditividade (velocidade e comprimento), e um sistema empírico relacional de noções físicas (movimento físico e distância) oferece o princípio básico para o desenvolvimento da concepção cartesiana ontológica da natureza. A exigência de se empregar, na teoria física, conceitos mensuráveis e expressáveis em linguagem algébrica acaba por levá-lo a construir, e a estabelecer como legítima, uma natureza mecânica do mundo. A extensão e o movimento, sendo passíveis de tratamento algébrico, constituem-se, assim, em conceitos físicos e são, portanto, os elementos últimos do mundo.

Percebe-se, desse modo, que a concepção cartesiana acerca do que é ou não uma quantidade não se encontra estabelecida linguisticamente, mas de maneira ontológica. Da mesma forma, a distinção entre quantidade e qualidade é ontológica, e não linguística. Tal distinção, deve-se notar, resulta da concepção cartesiana da legitimação da física como física matemática. Para tanto, 
com efeito, esta última é identificada com a própria física mecânica. Além disso, podem-se observar também as sementes da teoria da medição como um critério de escolha, a partir dos recursos empregados por Descartes para a construção de teorias físicas. A ideia de uma teoria da medição resulta da imposição de que os conceitos físicos sejam mensuráveis.

Ao construir sua física mecânica, Descartes define as ideias simples que formam o núcleo conceitual básico de sua física mecanicista. Elas constituem os fundamentos últimos a partir dos quais tudo deve ser composto. No entender de Descartes:

Denominamos "simples" apenas aquelas coisas que conhecemos tão clara e distintamente que não podem ser divididas pela mente em outras conhecidas de maneira ainda mais distinta. A forma, a extensão e o movimento etc. são do primeiro tipo; todo o resto concebemos como, em certo sentido, sendo composto a partir deles. (Descartes 1985 b, p. 44.)

Essas ideias simples constituem as propriedades primárias da matéria, entendida, nesse contexto, como uma entidade puramente matemática e que possui, na extensão, seu principal atributo. Os critérios subjacentes para a escolha desses conceitos primitivos das teorias físicas são aqueles de uma teoria incipiente da medição, que estabelece tais conceitos como somente aqueles passíveis de serem medidos. No entender de Descartes, a única categoria que preenche essa propriedade é aquela da quantidade (Id., 1984a). Não há lugar para qualidades no mundo quantificável da ciência cartesiana; elas são desqualificadas como noções primárias por não serem representáveis algebricamente, isto é, não podem ser interpretadas como quantidades.

Tendo estabelecido o problema da natureza da teoria física, Descartes busca também demonstrar que as teorias físicas proporcionam conhecimento teórico do mundo externo. A solução por ele apresentada do problema relativo à objetividade da ciência encontra-se alinhada com sua concepção de verdade. Os objetos 
de conhecimento humano são representações na mente. Sem um acesso direto ao mundo real, como se pode garantir a objetividade das representações?

Descartes obtém a garantia epistemológica de que as ideias inatas são representações de coisas reais no mundo por meio de considerações puramente metafísicas, acerca da natureza de nossas faculdades do conhecimento e da natureza de Deus. Ele garante, assim, a aplicação da teoria da correspondência da verdade aos conceitos mecânicos básicos, por ele considerados como ideias inatas. Tais conceitos representam objetos no mundo. Desse modo, através da dedução, a objetividade da base espalha-se por todo o sistema. Esse sistema cartesiano de princípios (noções comuns) garante que a dedução (coleção de intuições) leve de verdade a verdade, tencionando mostrar que o mundo mecânico conceitual constitui-se não apenas em uma representação possível do mundo, mas em uma representação fiel do mesmo.

Essa discussão da objetividade das ideias caracteriza a abordagem cartesiana do problema do conteúdo cognitivo da teoria física como metafísica. Semelhante abordagem parece constituir-se na única solução coerente para uma concepção de racionalidade que possui um caráter matemático e lógico, e busca contemplar, de maneira absoluta, o valor objetivo da teoria.

O projeto cartesiano de construção de um sistema axiomático ideal revela-se bastante difícil e cheio de obstáculos como reconhecido pelo próprio Descartes quando diz: "Na medida em que eu tenha examinado tudo de maneira ordenada, é certo que aquilo que ainda permanece a ser descoberto é em si mesmo mais difícil e mais recôndito que qualquer coisa que, até o momento, eu tenha sido capaz de descobrir" (Descartes, 1985a, p. 147-148).

Em primeiro lugar, o problema consiste em seguir a cadeia inteira de raciocínios, que parte dos primeiros princípios até obter a determinação explicativa de um fenômeno particular ou de uma lei. Essa é uma barreira praticamente intransponível. A brevité de la vie e o défaut des expériences são dois fatores que tornam 
a ideia de ciência uma impossibilidade prática (Descartes, 1985a). Ora, a aplicação dessa concepção axiomática ideal da ciência na explicação dos fenômenos físicos não pode ser implementada na ausência do conhecimento dos primeiros princípios, bem como das conexões entre eles e as leis empíricas. Em geral, entretanto, o conhecimento de tais conexões (necessárias e essenciais) entre a base teórica e a empírica não se encontra disponível. Por outro lado, deve-se lembrar que a ontologia cartesiana torna a extensão o atributo essencial da matéria. Essa tese inviabiliza uma teoria atomista da matéria. Segue-se que a concepção cartesiana de ciência como um método axiomático ideal não pode tolerar o emprego de hipóteses atômicas.

Contudo, para operacionalizar sua teoria da coerência da verdade, e mesmo seu sistema axiomático ideal, Descartes decide, ainda que de maneira provisória, empregar hipóteses. Tal emprego, entretanto, parece uma contingência da aplicação de sua teoria mecânica para explicar fenômenos físicos, exigindo uma teoria atomista da matéria. Sua metodologia emprega essa teoria como um meio para articular, e, mesmo, tornar efetiva, a aplicação de sua teoria mecânica. Desse modo, pode-se diminuir o hiato entre os primeiros princípios e as leis empíricas através da hipostasiação de uma teoria da matéria à qual se atribuem propriedades mecânicas. Trata-se aqui de fazer uso de modelos de massas invisíveis em movimento. No entender de Descartes, é o uso da ciência para os propósitos práticos, onde a brevité de la vie constitui um fator decisivo, que requer o emprego temporário de hipóteses para contornar o tempo infinito requerido para o estabelecimento da ciência ideal, isto é, a dedução de toda a física a partir da metafísica.

Como uma consequência da impossibilidade prática do desenvolvimento pleno da ciência ideal, e com o propósito de aprimorar o conhecimento prático dos fenômenos naturais, Descartes emprega metodologicamente a teoria atomista (hipotética) da matéria. Ele postula sistemas materiais de corpúsculos definidos (três tipos de corpúsculos) cujos movimentos, tamanho, figura e ação 
mecânica são responsáveis pela produção de todos os fenômenos naturais. Premida pela necessidade de apresentar explicações articuladas em ciência, essa nova estrutura do ser (extensão, tamanho e movimento) concebe o mundo como uma máquina, composta por corpos inertes movidos pela necessidade física e unificados pelas leis mecânicas que são expressas justamente em termos de figura, tamanho e movimento. Eles são os constituintes dos modelos mecânicos formados de massas invisíveis em movimento que caracterizam a abordagem sintética da mecânica ainda que organizadas segundo o princípio da unidade lógica. A ciência cartesiana como uma cadeia rigorosa e completa de razões, partindo de Deus até a particularidade dos fenômenos físicos, permanece, entretanto, um ideal ao qual a ciência prática e provisória gradualmente se aproxima.

Pode-se dessa forma, perceber com clareza, em Descartes, uma tensão entre duas concepções de teoria física. Por um lado, semelhante teoria é concebida como um sistema axiomático ideal, baseado em conceitos bem fundados e em princípios autoevidentes; isto é, todos os fenômenos físicos devem, em princípio, ser deduzidos de tais conceitos e princípios, e organizados segundo uma unidade lógica. Por outro, trata-se de uma definição que estabelece, através do uso de representações figurativas ou de modelos, os vínculos entre o sistema conceitual mecânico e a própria base empírica. Tais modelos mecânicos, massas invisíveis em movimento se encontram baseados em mecanismos definidos e concretos da matéria em movimento, em vez de empregarem uma cadeia rigorosa de razões lógicas.

Esses modelos mecânicos de massa invisíveis em movimento possuem o estatuto de hipóteses e não de pressupostos autoevidentes. O equilíbrio entre a definição de teoria física como um sistema axiomático ideal e as teorias físicas efetivas, que empregam hipóteses atomistas, proporciona as condições teóricas para definir a síntese cartesiana entre as certezas metafísica (científica) e moral (prática). Tal equilíbrio explica tanto o valor objetivo (me- 
tafísico), como prático (moral) da teoria física (Descartes 1985a). A ideia de uma teoria axiomática ideal da física é essencial para explicar racionalmente a objetividade da ciência (conhecimento teórico) bem como o comprometimento de Descartes com um valor objetivo (metafísico) das teorias físicas efetivas. Tais teorias não partilham das condições exigidas pela teoria física ideal, uma vez que empregam hipóteses como cadeias intermediárias.

A questão, assim, imediatamente se coloca: como explicar o conhecimento teórico proporcionado pelas mesmas? Tal conhecimento teórico constitui-se através da relação entre essas teorias (efetivas) e o sistema axiomático ideal que representa o mundo. Descartes parece entender que o valor objetivo (conhecimento teórico) das teorias físicas efetivas é definido em termos de sua contribuição para aproximá-las da teoria física ideal, ou seja, para o próprio conhecimento desta última teoria. O aumento no conhecimento das leis empíricas e das relações entre tais leis e o sistema conceitual mecânico diminui a variedade de hipóteses alternativas que vinculam princípios autoevidentes à base empírica. Isso leva a uma ampliação do conhecimento das relações essenciais (reais) e necessárias entre essas duas bases, o que caracteriza o valor objetivo das teorias físicas efetivas. A relação entre a base do conhecimento, organizado na forma geométrica, e as leis empíricas, que são construídas orientadas pela base teórica, não é sempre uma relação de estreita dedução matemática ainda que o objetivo seja esse.

No entanto, como não é possível conhecer imediatamente as relações essenciais entre a base e as leis empíricas descrevendo os fenômenos, procura-se substituir estas por uma sequência de hipóteses sobre as conexões que podem consistir em modelos hipotéticos sobre a natureza destas relações. Na relação entre a base do conhecimento estabelecida a priori por Descartes e as leis empíricas elaboradas pelo método experimental, com a ajuda da orientação da base teórica, encontra-se um dos aspectos fundamentais do funcionamento do método de solução de problemas de Descartes. 
O método analítico funciona para resolver problemas considerando a base e assumindo as leis empíricas como a solução do problema e, então, procurando descobrir, com a ajuda da base e das leis empíricas, as hipóteses intermediárias que as conectam. A sua abordagem ao problema da fundamentação das leis da ótica é exemplar nesse sentido. Descartes considera que a metafísica tem dado as condições para afirmar que as leis da mecânica proporcionam um conhecimento certo da natureza física. Descartes conhece também, e é um dos que ajudaram a elaborar, a lei da refração, e considera bem estabelecido o conhecimento da lei da reflexão da ótica. Contudo, essas leis adquirem o estatuto de conhecimento certo apenas e tão somente se forem deduzidas matematicamente da base da mecânica.

O método analítico procura elaborar os meios para a construção das hipóteses intermediárias que Descartes constrói com a ajuda de modelos mecânicos de que a natureza da luz é formada de partículas (Descartes, Regra VIII, [1985b]; 1963, p.114). Com esses recursos, ele consegue construir uma conexão hipotética, portanto, provisória, entre a base mecânica e as leis da ótica. Esse conhecimento por envolver provisoriamente hipóteses tem o estatuto de certeza moral. O avanço do conhecimento sobre a natureza deverá transformar essa certeza moral em certeza metafísica que expressa o conhecimento da relação essencial entre esses dois conjuntos de leis.

O valor prático da teoria é dado através de sua aplicação à natureza, constituindo uma relação entre teoria física e o mundo dos fenômenos. Por exemplo, as teorias físicas podem auxiliar-nos a aprimorar nossos métodos para construir e polir lentes, construir máquinas mais eficientes etc. Hipóteses acerca da natureza das coisas e das relações entre os princípios básicos e as leis empíricas encontram-se bem ajustadas a essa função da ciência como uma forma de ação sobre a natureza.

Na concepção de Descartes, encontra-se também o componente que o conhecimento das causas eficientes é um conheci- 
mento que permite a conquista e o domínio da natureza. Esse conhecimento tem uma finalidade prática que é o uso das leis da natureza para promover o bem-estar social, como, por exemplo, a produção de lentes cada vez mais eficientes com a ajuda do conhecimento das leis da ótica. A ciência das causas eficientes que se conhece por meio do método racional é uma concepção de ciência que traz, atada a si, uma tecnologia de apropriação e reprodução da natureza. Conhecer a natureza é conhecer as causas eficientes dos fenômenos, os quais permitem suas reproduções indefinidas.

O uso da ciência para a produção de tecnologia requer uma combinação das causas eficientes com as causas finais. A aplicação do conhecimento científico requer uma análise dos fins para os quais se pretende fazer uso. O caso da construção das lentes é exemplar, na medida em que ele requer não apenas o conhecimento das leis da ótica, mas também a análise do olho humano em termos de suas funções e fins. A eficiência da tecnologia, que consiste na construção de artefatos, dependerá fundamentalmente dessa combinação de análise envolvendo as causas eficientes dos fenômenos e as causas finais dos objetivos pretendidos com sua construção.

Essa relação da ciência e da tecnologia terá uma influência fundamental na concepção da política como ciência em Hobbes, assim, do mesmo modo, na concepção do direito como ciência e como tecnologia.

A reação contra a concepção metafísica da ciência, como herdeira da proposta de Descartes, emerge no final do século XIX com as propostas da teoria física como representação tanto por parte de Duhem quanto de Poincaré, que dão origem a uma nova concepção de racionalismo que denominamos de racionalismo neoclássico (Chiappin, 2010). Contudo, Duhem se separa de uma concepção metafísica da ciência sem ser antimetafísico, preservando a metafísica como um domínio formado de ideias reguladoras e elementos extralógicos, os quais considera essencial 
na elaboração da concepção da ciência que pretende se demarcar da metafísica e evitar a concepção convencionalista/pragmatista de Poincaré, que se posiciona como antimetafísica. A proposta de concepção de Duhem de ciência constitui-se, por sua vez, em uma doutrina de transição, com a construção do programa do racionalismo neoclássico, entre uma epistemologia com sujeito, que é a teoria da ciência de Descartes, característica da posição cartesiana e de toda teoria do conhecimento clássica, e uma epistemologia pura, sem sujeito, preconizada por Popper. O conceito básico para essa passagem é a noção duhemiana de representação como um signo linguístico (Duhem 1974), e não como algo mental cujo objetivo é a organização matemática das leis empíricas. Duhem substitui o sujeito transcendental (o Cogito, o sujeito ideal do conhecimento) por uma teoria física transcendental (a teoria física ideal) e pressupõe que o acesso a ela se dá por uma dinâmica do conhecimento compatível com outra de suas teses que afirma que o indivíduo é falível. Portanto, Duhem defende uma concepção realista da ciência, mas, diferentemente da de Descartes, a verdade não está no início do sistema, mas no final, como uma teoria ideal a ser buscada pela dinâmica do conhecimento. Além disso, o realismo de Duhem, diferentemente do de Descartes, não é corpuscular ou atomista, uma vez que ele rejeita a teoria da matéria, e a substitui pelas estruturas de organização das leis, constituindo-se em um realismo estrutural e convergente (Chiappin 1989)

O racionalismo clássico construído por Descartes, que tem a teoria mecânica como modelo e princípio unificador da física, é substituído, com Duhem, pelo racionalismo neoclássico, com a tese de que a termodinâmica é agora o princípio unificador da física mais compatível com sua concepção de um realismo estrutural. Contudo, para Poincaré também, um dos construtores do racionalismo neoclássico, o princípio da unidade lógica da ciência deve ser rejeitado e substituído pelo princípio da subdeterminação das teorias pelos dados. 
A mecânica analítica e a termodinâmica e o eletromagnetismo são construídos de maneira autônoma segundo a abordagem da mecânica analítica que é interpretada, por Duhem, como uma linguagem e não propriamente uma mecânica. Poincaré mantêm-se adepto desta concepção da mecânica e será o seu principal promotor moderno.Contudo, rejeitará a possibilidade do método experimental de escolher entre teorias ou hipóteses. Segundo Poincaré, onde se pode construir um modelo mecânico podem-se construir infinitos. Com esta conclusão, a ciência, para ele, não pode possuir um valor objetivo mas apenas prático. Ele desenvolverá uma concepção convencionalista/pragmatista da ciência a partir de suas reflexões acerca da irrefutabilidade da mecânica e da importância do princípio da subdeterminação da teoria pelos dados na ciência.

O sujeito transcendental de Descartes e de Kant é absolutamente essencial para garantir que o conhecimento da natureza é um conhecimento com certeza e, além disso, que o modelo da cascata contém uma dinâmica capaz de explicar o desenvolvimento do conhecimento, ainda que fazendo uso de um modelo estático do conhecimento que é o modelo geométrico. Em Duhem, o sujeito transcendental é substituído por um indivíduo falível que não tem acesso direito à verdade. A ideia assim é a de desenvolver uma estratégia dinâmica para ter acesso indireto à verdade expressa na forma de uma teoria física ideal. Esse acesso se dará sempre de maneira assintótica. O modelo estático da geometria é substituído por uma concepção da dinâmica das teorias científicas interpretadas como hipóteses e que devem ser eliminadas de modo sistemático e racional, fazendo com que ocorra uma aproximação sucessiva da teoria física ideal. 


\section{Bibliografia}

BACON, FANCIS. Novum organum, Of true directions concerning the Interpretation of nature. Illinois: Open Court Publishing Company, New Edition, 1994.

Novum Organum. Coleção os Pensadores. São Paulo: Abril, 1984 .

CHIAPPIN, J. R. N. Duhem's theory of science: the interplay between Philosophy and history of science. Ph. D Thesis. University of Pittsburgh. U.S.A, 1989.

"Racionalidade, Decisão, Solução de problemas e o programa racionalista”. Ciência e Filosofia. V.5. 1996.

CHIAPPIN, J. R. N \& LEISTER, Ana Carolina. "Uma reconstrução racional do programa de pesquisa sobre o racionalismo neoclássico: os subprogramas do convencionalismo/ pragmatismo (Poincaré) e do realismo estrutural convergente (Duhem)”. Trans/form/ação. Vol.34. n. 2, 2011.

DESCARTES, R. La Dioprique. In Oeuvres Philosophiques. Tome I. Paris: Édition Garnier Frères. 1963a.

Les Météores. In Oeuvres Philosophiques. Tome I. Paris: Éditions Garnier Frères. 1963b.

Les Meditations. Les objections Et les réponses. Tome II. Paris. Édtions Garnier Frères, 1967.

Regras para a direção do Espírito. Lisboa: Estampa, 1971.

Medidations on first philosophy. In John Cottingham, Robert Stoothoff and Dugald Murdoc (editors), The Philosophical writtings of Descartes. Cambridge: Cambridge University Press, 1984a.

The Objections and Replies. In: John Cottingham, Robert Stoothoff and Dugald Murdoc (editors), The Philosophical writtings of Descartes. Cambridge: Cambridge University Press, 1984b.

Discourse on the method. In: John Cottingham, 
Robert Stoothoff and Dugald Murdoc (editors), The Philosophical writtings of Descartes. Cambridge: Cambridge University Press, 1985 a.

DESCARTES, R. Rules for the Direction of the Mind. In: John Cottingham, Robert Stoothoff and Dugald Murdoc (editors), The Philosophical writtings of Descartes. Cambridge: Cambridge University Press, $1985 \mathrm{~b}$.

The Principle of Philosophy. In: John Cottingham, Robert Stoothoff and Dugald Murdoc (editors), The Philosophical writtings of Descartes. Cambridge: Cambridge University Press, $1985 \mathrm{c}$.

DUGAS, RENE. A History of Mechanics. New York: Dover Publications, INC., 1988.

DUHEM, PIERRE. "Physique et Métaphysique". Revue des Questions Scientifiques 34:55-83, 1893 b.

"L'École Anglaise et les Théories Physiques, à propos d'un livre de W. Thompson". Revue des Questions Scientifiques 34:345-378, 1893c.

"L'évolution des Théories Physiques du XVII siècle jusqu'à nos jours”. Revue des Questions Scientifiques 40:463499, 1896a.

L'évolution de la mécanique. Paris: A. Hermann, 1905.

"La Valeur de la Théorie Physique, à propos d'un livre récent". Revue Générale des Sciences Pures et Appliquées XIX:7-19, 1908.

The aim and Structure of Physical Theory. Atheneum Press, 1974 .

Evolution of Mechanics. The Netherlands: Sijthoff \& Noordhoff, 1980.

To Save the Phenomena. Chicago: University of Chicago., 1985.

GALILEI, Galileo. Dialogue Concerning the Two Chief World Systems. New York: Prometheus Book. 1991. 
GALILEI, Galileo. Dialogue Concerning two new sciences. New York: Dover Publications. 1954.

HOBBES, THOMAS. Leviatã. Coleção os Pensadores. São Paulo: Abril. 1974 .

KOYRÉ, ALEXANDRE. Études Galiléennes. Paris: Hermann. 1966

KOYRÉ, ALEXANDRE. Do Mundo Fechado ao Universo Infinito. São Paulo: Forense, 1979.

MACH, ERNST. Science on Mechanics: A critical and historical account. La Salle: The Open Court Publishing Co., 1960.

NEWTON, I. Opticks. London: Dover Publications, 1952.

SILVA, C. C. "A teoria das cores de Newton: um exemplo do uso da história da ciência em sala de aula". Ciência e Educação. v. 9 n.1. P. $53-65.2003$.

SILVA, C.C e MARTINS, R. A. A Nova teoria das cores de Isaac Newton: uma tradução comentada. Revista Brasileira de Ensino de Física, v.18, p.313-217, 1996. 
